\title{
BMTC Pay - An Android Based Project on Digital Payment System in Buses
}

\author{
Rahul Kumar Jaiswal, Sagar Thapa, Akash Kumar Yadav, Aneev Amit, Manju More E
}

\begin{abstract}
As per the current scenario, the payment systemused in buses is same old way of getting the ticket from the conductor. This is way more time taking since providing with the correct amount (change) is not possible every time. Also communication takes more time as compared to digital booking.For example; the bus conductor has to print tickets for every passenger after knowing their respective stoppage which takes comparatively more time as compared to digital payment.The main idea behind this project is to collect the fare automatically using digital payment system. It will be designed to make travelling more comfortable for the people.Carrying changes will no longer be a problem and keeping an eye on the transactions will no longer be a headache for the government as well as for the passenger.
\end{abstract}

Index Terms - Android Application, Digital Payment, Public Transportation, Road Transport.

\section{INTRODUCTION}

Highlight Today, everything in the world is smart and digitalized. Many advances have been made in the transportation sector too. However, public transport buses in India have always been an area where such new advances have turned their faces out.Buses connects villages and towns which are located at rural and remote places. Demand of passengers for using bus network is higher because of being cheap and also because of having more coverage area.So as per this project is concerned, the bus payment system would be different from that of the traditional way of paying.There will be an interactive screen at the entrance of the bus where one has to choose the destination of his journey.After submitting the detail, a QR code will begenerated which has to be scanned through the mobile application.The app contains the userinformation along with an e-wallet for the payment. After a successful payment, a ticket would be generated. Mobileticketingmodel comprises of a registered Id. By scanning at the entrance or at the exit of the vehicle, thepassenger can start using the service. The main

drawback of this system is the use of smart phone.

Rahul Kumar Jaiswal, UG Student, School of Computing \& IT, REVA University, Bangalore, Karnataka

Sagar Thapa, UG Student, School of Computing \& IT, REVA University, Bangalore, Karnataka

Akash Kumar Yadav, , UG Student, School of Computing \& IT, REVA Uiversity, Bangalore, Karnataka

Aneev Amit, UG Student, School of Computing \& IT, REVA University, Bangalore, Karnataka

Manju More E ,Assistant Professor, School of Computing \& IT, REVA University, Bangalore, Karnataka
Peoplewith simple phones which does not have any internet facility cannot use this technology. But with advancement of people and their interest in the field of digitalization, this tech will be more in use than the previous way of payment.

\section{LITERATURE SURVEY}

Automated Bus Fare Collection System using RFID was the paper presented by Sunitha Nandhini A - Assistant Professor,Department of Computer Science and Engineering,Sri Krishna College of Technology, CoimbatoreSangeetha $\mathbf{G}$ and Vidhya Janani J - UG Scholor,Department of Computer Science and Engineering,Sri KrishnaCollege of Technology, Coimbatore in IJARCET(International Journal of Advanced Research in Computer Engineering \& Technology) Volume 6, Issue 3, March 2017, ISSN: 2278_1323.The project was implemented using RFID/Smart Card which is given to the passenger. When the passenger gets into the bus he has to swipe the card in the RFID reader and he has to a destination point in the device will automatically calculates the fare and deduct the money automatically. Hence people do not have to carry the money and they don't have the problem in giving the right change to conductor. Conductor also feels free in collecting the money from the people. All the record will updated automatically in the server continuously. When more people are travelling than it's also easy to give the ticket. A based web-page monitors the bus for amount path taken bus status number of passengers distance information.It overcomes all the problems faced in bus with IOT based web-page monitor system.Automated fare collection (AFC) systems are used in many urban public transport systems around the world. As the designation suggests, these are typically designed with the specific purpose of automating the ticketing system,easing public transport use for passengers and adding efficiency to revenue collection operations.As per the current scenario, the payment system used in buses is same old way of getting the ticket from the conductor. This is way more time taking since providing with the correct amount(change) is not possible every time. Also communication takes more time as compared to digital booking.For example, if a passenger wish to travel in bus. He has to carry money with them. Then conductor will collect the money and he will give ticket. This has to repeat for all passengers. This will take more time and waste of human resource as well as energy. The data relate to an AFC system integrated with an automatic vehicle location system that records a transaction for each passenger boarding a bus, containing attributes regarding the route, the vehicle, and the travel card used, along with the time and the location 
where the journey began. Some of these are recorded for the purpose of allowing on board ticket inspection but additionally enable innovative spatial validation features introduced by the methodology.Thus, in our project we tried to build a payment system which not only helps in paying digitally but also helps in maintaining the details of the passengers along with the bus details. This application helps in generating the bus ticket on a single click. It is also capable of managing the details about fare of the bus, source and destination.It manages the details of the passenger and their charges details and booking details separately.Despite the present functionality of the designed software, an additional functionality such as the use of E-mail to send tickets and notifications to the customer can be implemented into the system. The design of this application will be beneficial to the company because it has not existed before.

\section{OBJECTIVES}

- The main aim here is to avoid carrying change(in terms of coins) for the bus fare.

- Implementation of this system can improve cleanliness in the bus as well as the surrounding areas as the tickets will be digitalized instead of being made of paper.

- Digitalmode of payment not only eliminates risk of using fake notes but also keeps an eye on the day earnings. For example, many conductors doesn't provide ticket for his passenger and the money taken from them goes directly to his pocket which is considered to be black money.

- It's a small step towards Digital India.

- Further, our objective would be to expand this project in connecting different cities with much more powerful database and system design.

\section{EXISTING SYSTEM}

In general, the system of a bus comprises of a bus driver, bus conductor and the passengers. The passengers collects their ticket from the conductor on paying certain amount. They are provided with paper tickets generated from handheld machines. They have to carry those tickets until they reach their respective stoppage.

This system has many disadvantages:

- The passenger will have to carry their ticket until they reach their respective stoppage.

- It shouldbe ensured that everyone has got their ticket along with the correct change.

- The current system consumes more time. From printing the ticket till giving back the exact change, it requires communication between the passenger and the conductor.

- Carrying change each and every time in the bus is very difficult for the conductor as well as the passenger.

\section{SYSTEM DESIGN}

This project will work using a mobile app which will have all the necessary inputs and information of the user. We will make use of MySql server to store the database of the passenger using query language. Also for making the mobile application we are making use of android studio where we code in java. The setup requires operating system - Windows 7 and above and SDK for android 4.2 along with android studio 2.0 and above.

\section{ADVANTAGES}

- Reduction in waiting time using digital mode of payment.

- E-tickets results in not using paper tickets which is one of the best way to reduce pollution and in saving the environment.

- Service extension from bus trip saving.

- Elimination of fake notes and loss of revenues will be reduced to a great extent.

- Carrying exact change (in terms of coins) would no longer be a problem.

\section{DISADVANTAGES}

- Inconvenience from change of service

- More packed buses.

- Needs an active internet connection.

- People with normal phones won't be able to use this service.

\section{RESULTS}

The system will be simple, user friendly, and will be made secure. This technology will be much more convenient compared to the paper based ticketing system. Below are some of the screenshots taken from the mobile application.

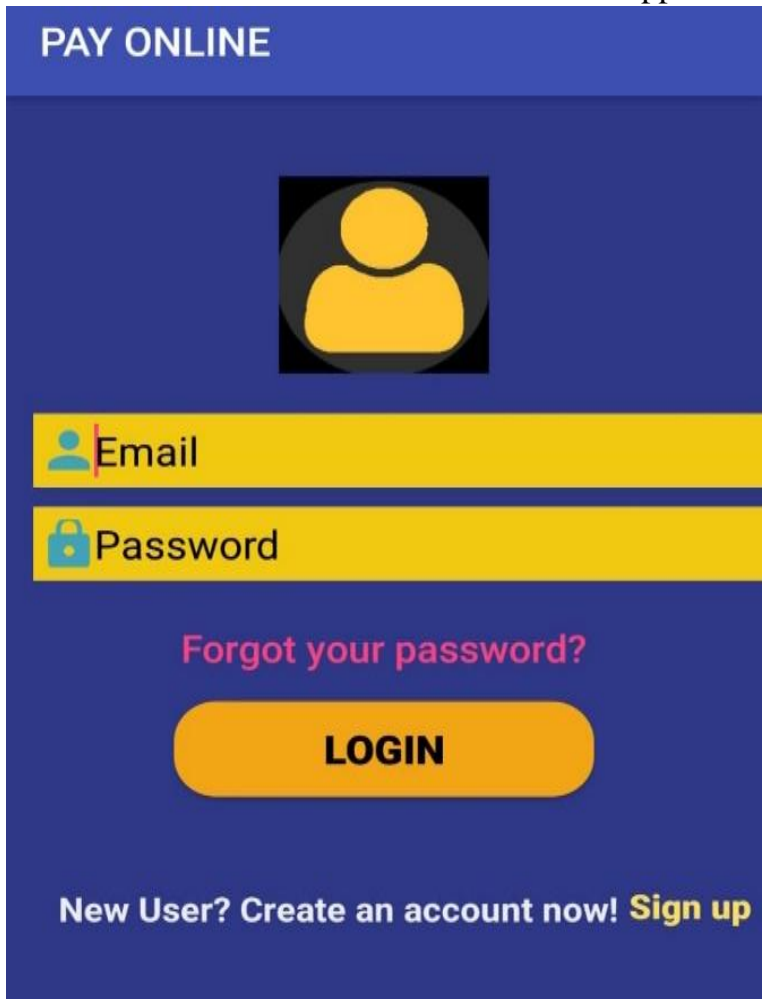

Fig. 1The Login Page where registered users needto login using their username and password 


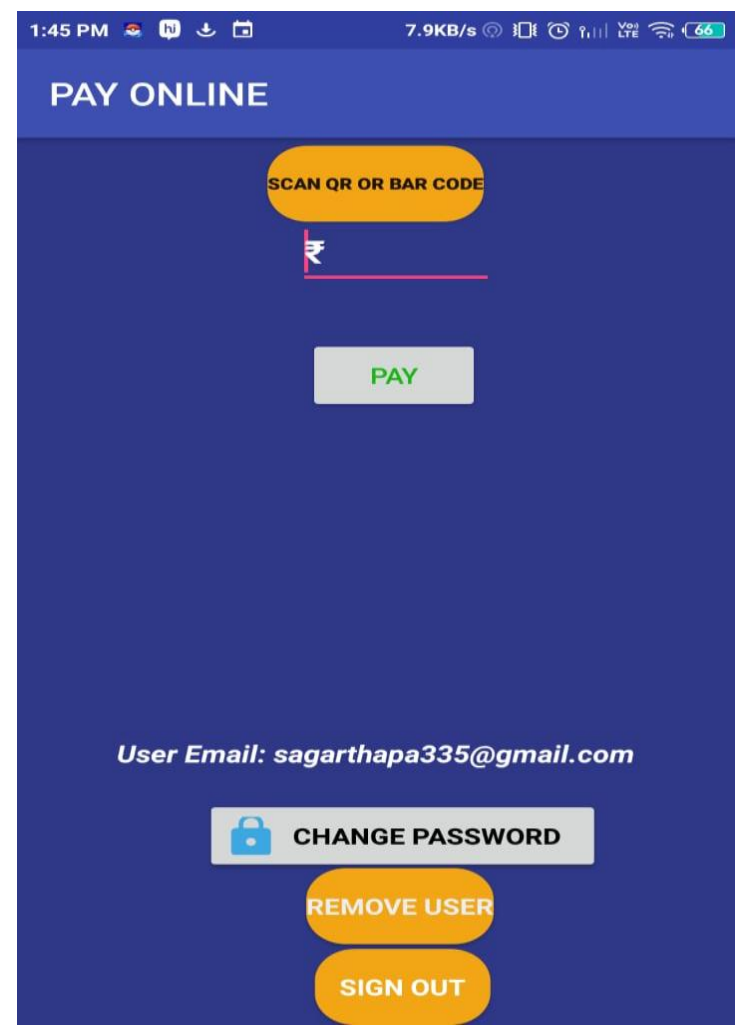

Fig. 2On logging in we get a screen where Scan and Pay are available along with the option of changing the password

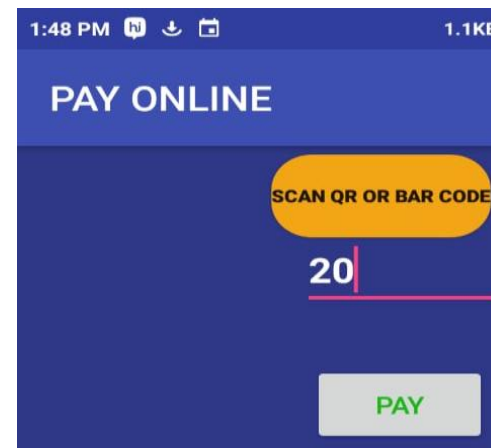

User Email: sagarthapa335@gmail.com

\section{CHANGE PASSWORD}

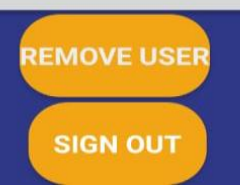

Fig. 3After scanning the QR code, the amount will be displayed which is to be payed for that particular route

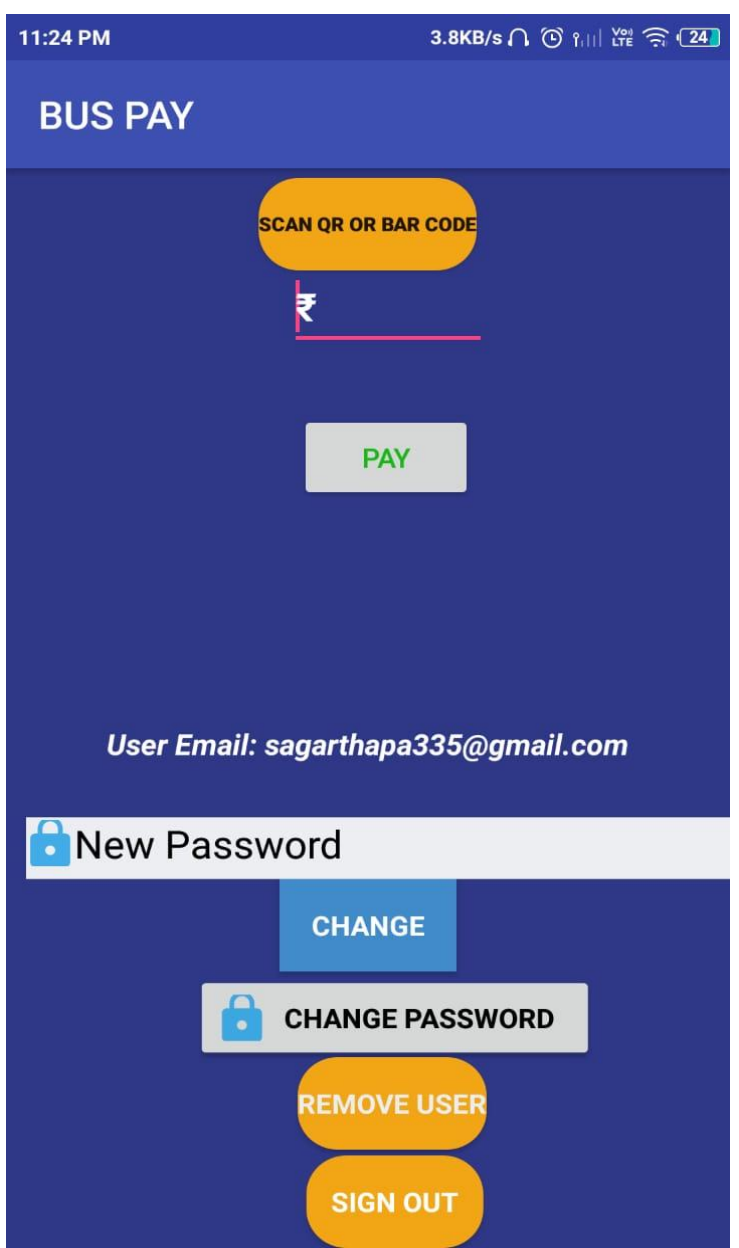

Fig. 4Change Password option can be used to assign a new password for the current user

\section{FUTURE WORK}

The project can be further modified and more features can be added to ensure safe and comfortable travel. The application will be made in such a way that it supports multiple payment option for more convenient way of paying. Moreover real time tracking of the buses can be done using more powerful algorithms. Not only this system can be implemented in local cities but also can be further extent to inter-cities. Further, more security features can be added up in the system using more secure way of signing in.

\section{CONCLUSION}

The current system has many issues and disadvantages. Whereas the proposed system overcomes all the drawbacks. This system not only promotes Digital India but also attracts many people towards the using new technology. Use of this system reduces payment time. Also the passenger's information are securely saved on the database along with their travel history.Overall this project is implemented to make payment during travelling more convenient and more user friendly. This system is suitable for metro cities like Bangalore where a large number of customers use public transport on a daily basis. 


\section{REFERENCES}

[1] W. Wang, J. P. Attanucci, and N. H.M. Wilson, -Bus passenger origindestination estimation and related analyses using automated data collection systems, $\| \mathrm{J}$.

Public Transp., vol. 14, no. 4, pp. 131-150, 2011.

[2] J. Zhao, A. Rahbee, and N. H. M.Wilson,-Estimating a rai passenger trip origin-destination matrix using automatic data collection systems, $\|$ Comput. Civ. Infrastruct. Eng., vol. 22, no. 5, pp. 376-387, Jul.2007

[3] M. A. Munizaga and C. Palma, -Estimation of adisaggregate multimodalpublic transport Origin-Destination matrix from passive smartcard datafrom Santiago, Chile, Transp. Res. C, Emerg. Technol., vol. 24, pp. 9-18,Oct.2012.

[4] M. Munizaga, F. Devillaine, C. Navarrete, and D. Silva, -Validating travelbehavior estimated from smartcard data, Transp. Res.C, Emerg. Technol., vol. 44, pp. 70-79, Jul. 2014.

[5] M. Trépanier, N. Tranchant, and R. Chapleau, card automated fare collection system,\| J. Intell. Transp. Syst. Technol. Plann., Oper., vol. 11, no. 1, pp. 1-14, 2007

[6] J. M. Farzin, - Constructing an automated bus origin-destination matrix using farecard and global positioningsystem data in São Paulo, Brazil,„ Transp. Res. Rec. J.Transp. Res. Board, vol. 2072, pp. 30-37, Dec. 2008

[7] D. Li, Y. Lin, X. Zhao, H. Song, and N. Zou, Database Systems for Advanced Applications, J. Xu, G.Yu,S.Zhou, and R. Unland, Eds. Berlin, Germany: Springer-Verlag, 2011, pp. 502 $-513$

[8] J. B. Gordon, - Intermodal passenger flows on London's public transport network: Automated inference of full passenger journeys using fare transaction and vehicle-location data, M.S. thesis, Dept. Urban Stud. Plann.,Mass. Inst. Technol., Cambridge, MA, USA, 2012 